\title{
Successful maternal and fetal outcome of pregnancy following heart valve replacement using a sequential anti coagulation regime
}

\author{
Pooja Tandon*, Suman Puri, Balpreet Kaur, Shreeswasti Chaondwal, Supriya Gupta
}

Department of Obstetrics \& Gynaecology, DMC\&H, Ludhiana, Punjab, India

Received: 12 April 2015

Accepted: 09 May 2015

\author{
*Correspondence: \\ Dr. Pooja Tandon, \\ E-mail: drpoojatandon77@gmail.com
}

Copyright: ( ) the author(s), publisher and licensee Medip Academy. This is an open-access article distributed under the terms of the Creative Commons Attribution Non-Commercial License, which permits unrestricted non-commercial use, distribution, and reproduction in any medium, provided the original work is properly cited.

\begin{abstract}
Background: Patients with mechanical heart valves require anticoagulation which is associated with significant maternal mortality (1-4\%) and fetal complications (31\%) in pregnancy.

Methods: A prospective study was carried out enrolling pregnant patients with mechanical heart valves who were booked at our institution for antenatal care, managed using a sequential anticoagulant regime consisting of warfarin and low molecular weight heparin and delivered at our utility over two years.

Results: We had seven cases of pregnancy following heart valve replacement over a period of two years with no fetal malformations and successful maternal outcome (71.43\% term deliveries).

Conclusions: LMWH until $13^{\text {th }}$ week of gestation, followed by warfarin until late third trimester (36 weeks), then restarting LMWH until delivery in pregnant patients with mechanical heart valves was associated with successful maternal and fetal outcome.
\end{abstract}

Keywords: Heart valve replacement, Pregnancy, Anticoagulant

\section{INTRODUCTION}

Worldwide many prosthetic valves are yearly implanted in girls and young women with rheumatic or congenital heart disease. There are two major groups of artificial heart valves; mechanical and bioprosthetic valves. Mechanical prostheses, bioprostheses and native valve disease each carry specific risk during pregnancy. Women with Mechanical prosthetic valves require anticoagulation which is associated with risks to the mother and the foetus in pregnancy. Hypercoagulability of pregnancy causes an increased incidence of mechanical valve thrombosis pregnant women who require antithrombotic therapy pose a therapeutic dilemma regarding the choice of antithrombotic agents in pregnancy.

From the maternal perspective, warfarin therapy is currently the safest and most efficacious regimen to prevent thromboembolic events; it is considered safer than heparin therapy or combined regimens. ${ }^{1}$

However, warfarin has well-documented teratogenic effects. $^{2,3}$ The period of greatest vulnerability to develop the warfarin embryopathy following exposure is between the sixth and twelfth weeks of gestation. ${ }^{4}$ Using heparin alone during pregnancy eliminates fetal risks; however, multiple case reports of thrombosed valves causing maternal morbidity and mortality have raised serious concerns. ${ }^{5-8}$ The use of heparin instead of an oral anticoagulant after conception during the sixth and twelfth weeks of gestation and late third trimester has been advocated, but this is associated with hemorrhagic complications like fetal intracranial microhemorrhage and fetal loss from abortion and stillbirth due to placental separation and hemorrhage. ${ }^{4,9}$ 


\section{METHODS}

We studied seven pregnant patients following mechanical valve replacement over a period of two years (August 2011 to August 2013) booked as antenatal cases at our centre. Balancing the risks - maternal morbidity and mortality - from thromboembolic complications and fetal loss and embryopathy, we substituted warfarin with LMWH in the $6-12^{\text {th }}$ weeks of gestation and in the late third trimester for our antenatal patients and found successful outcomes for both the mother and the fetus. The dose of LMWH was calculated on the basis of weight of the patient. INR was monitored while the patients were on oral anticoagulants (warfarin) and the target INR was set to be 2-3.

\section{RESULTS}

Of the seven women $4(57.14 \%)$ belonged to the age group of 21-25 years, two $(28.58 \%)$ to $26-30$ years and one $(14.28 \%)$ was between $31-35$ years (Table 1$)$. There were four $(57.14 \%)$ primi gravidas in the study (Table 2). All patients had an uncomplicated antenatal period.

Table 1: Distribution according to age.

\begin{tabular}{|lll|}
\begin{tabular}{|ll} 
Age \\
(years)
\end{tabular} & $\begin{array}{l}\text { No. of } \\
\text { patients }\end{array}$ & $\%$ \\
\hline $21-25$ & 4 & 57.14 \\
\hline $26-30$ & 2 & 28.58 \\
\hline $31-35$ & 1 & 14.28 \\
\hline Total & 07 & 100 \\
\hline
\end{tabular}

Maximum number of patients belonged to the age group of 2125 years

Table 2: Distribution according to gravidity.

\begin{tabular}{|lll|}
\hline Gravidity & $\begin{array}{l}\text { No. of } \\
\text { patients }\end{array}$ & $\%$ \\
\hline 1 & 04 & 57.14 \\
\hline 2 & 02 & 28.58 \\
\hline 3 or more & 01 & 14.28 \\
\hline Total & 07 & $\mathbf{1 0 0}$ \\
\hline
\end{tabular}

Maximum number of patients were primigravidas

Two $(28.58 \%)$ patients had pre term delivery beyond 35 weeks and the rest delivered at term.

Three $(42.86 \%)$ patients underwent a lower segment caesarean section for fetal distress.

All the babies cried immediately post-delivery and were shifted to mothers. One patient needed relaparotomy on day 3 for pelvic hematoma drainage and another patient had postpartum hemorrhage after instrumental delivery which was managed medically.
Table 3: Distribution according to mode of delivery.

\begin{tabular}{|lll|}
\hline $\begin{array}{l}\text { Mode of } \\
\text { delivery }\end{array}$ & $\begin{array}{l}\text { No. of } \\
\text { patients }\end{array}$ & Percentage \\
\hline Vaginal & 2 & 28.57 \\
\hline Instrumental & 2 & 28.57 \\
\hline LSCS & 3 & 42.86 \\
\hline Total & 07 & $\mathbf{1 0 0}$ \\
\hline
\end{tabular}

Majority of the patients needed intervention during delivery

Table 4: Distribution according to period of gestation at delivery.

\begin{tabular}{|lll|}
\hline $\begin{array}{l}\text { Period of } \\
\text { gestation }\end{array}$ & $\begin{array}{l}\text { No. of } \\
\text { patients }\end{array}$ & $\%$ \\
\hline Pre term & 02 & 28.57 \\
\hline Term & 05 & 71.43 \\
\hline Post term & 00 & 00 \\
\hline Total & 07 & $\mathbf{1 0 0}$ \\
\hline
\end{tabular}

Majority of the patients delivered at term

\section{DISCUSSION}

Mechanical valves provide greater durability but with increased risk of thrombo embolic events whereas bioprosthetic valves provide better maternal and fetal outcome because they are spared the need of anticoagulation but most of the patients require re operation after 10 years because of valve deterioration. Pregnant women with prosthetic heart valves present with issues varying from increased risks to foetus with oral anticoagulation, increased risk of valve thrombosis, bleeding secondary to anticoagulation and accelerated Structural Valve Deterioration (SVD) of bioprosthetic valves.

Anticoagulation can be achieved using warfarin, UnFractioned Heparin (UFH), Low Molecular Weight Heparin (LMWH) or a combination of the above. The major difference between the two anticoagulants is that warfarin crosses placenta while heparin does not.

Vitale et al. ${ }^{10}$ reported 58 pregnancies in 43 women with mechanical heart valves who were treated with warfarin. There were 22 fetal complications among women requiring more than $5 \mathrm{mg} /$ day of warfarin to maintain an INR or 2.5 to 3.5 compared with 5 complications in those taking $5 \mathrm{mg} /$ day or less.

Using heparin alone during pregnancy eliminates fetal risks but multiple cases of thrombosed valves causing maternal mortality and morbidity have been reported. Heparin of either type provides less protection against valve thrombosis as compared to warfarin. Recommendations about the management of anticoagulation in pregnant women with mechanical heart valves are included in recent guidelines of the American College of Cardiology/American Heart Association 
(ACC/AHA $)^{11}$ and of the European Society of Cardiology (ESC). ${ }^{12}$ The level of evidence of these guidelines is $\mathrm{C}$ (i.e. based on consensus of experts and/or retrospective/small studies).

Recommended choices are as below:

1. High dose (17500-20000 U) subcutaneous UFH throughout pregnancy given twice daily with monitoring to guide dosing ( $6 \mathrm{hr}$ post dose APTT of twice the control level)

2. LMWH subcutaneous throughout pregnancy with anti Xa monitoring

3. UFH/LMWH as above until $13^{\text {th }}$ week of gestation, followed by warfarin until middle of third trimester, then restart UFH/LMWH until delivery.

We followed the third regime and found good pregnancy outcomes with no fetal malformations and $71.43 \%$ term deliveries. We encountered hemorrhagic complications in two patients that were dealt with immediately and the patients were discharged in satisfactory condition.

\section{CONCLUSION}

The choice of anticoagulant regimens for mechanical heart valve thromboprophylaxis during pregnancy should be made by balancing 2 risks - maternal morbidity and mortality and fetal loss and embryopathy. The practice of substituting oral anticoagulants for heparin in the first trimester potentially eliminates fetal embryopathy, but appears to subject woman to an increased risk of thromboembolism. We found successful pregnancy outcomes with this regimen after careful counselling of women with mechanical heart valves prior to or shortly after the diagnosis of pregnancy and discussion of the risks associated with available anticoagulant options.

\section{ACKNOWLEDGEMENTS}

We acknowledge to Dr. Suman Puri for research methods; Dr. Balpreet, Dr. Shreeswasti, Dr. Supriya for data collection; Dr. Pooja Tandon for manuscript writing and editing.

\section{Funding: No funding sources}

Conflict of interest: None declared

Ethical approval: Not required

\section{REFERENCES}

1. Oakley CM. Anticoagulants in pregnancy. Br Heart J. 1995;74:107-11.

2. Badduke ER, Jamieson WRE, Miyashima RT, Munro AI, Gerein AN, MacNab J, et al. Pregnancy and childbearing in a population with biologic valvular prostheses. J Thorac Cardiovasc Surg. 1991;102:179-86.

3. Oakley CM. Valve prostheses and pregnancy. $\mathrm{Br}$ Heart J. 1987;58:303-5.

4. Hall JG, Pauli RM, Wilson KM. Maternal and fetal sequelae of anticoagulation during pregnancy. Am J Med. 1980;68:122-40.

5. Ferraris VA, Klingman RR, Dunn L, Fein S, Eglowstein M, Samelson R. Home heparin therapy used in a pregnant patient with a mechanical heart valve prosthesis. Ann Thorac Surg. 1994;581168-70.

6. Golby AJ, Bush EC, DeRook FA, Albers GW. Failure of high dose heparin to prevent recurrent cardioembolic strokes in a pregnant patient with a mechanical heart valve. Neurology. 1992;42:2204-6.

7. Watson WJ, Freeman J, O'Brien C, Benson M. Embolic stroke in a pregnant patient with a mechanical heart valve on optimal heparin therapy. Am J Perinatol. 1996;36:371-2.

8. Hurwitz A, Milwidsky A, Medina A, Yagel S. Failure of continuous intravenous heparinization to prevent stroke in a pregnant woman with a prosthetic valve and atrial fibrillation. J Reprod Med. 1985;30:618-20.

9. Sareli P, England MJ, Berk MR, Marcus RH, Epstein $\mathrm{M}$, Driscoll J, et al. Maternal and fetal sequelae of anticoagulation during pregnancy in patients with mechanical heart valve prostheses. Am J Cardiol. 1989;63:1462-5

10. Vitale N, De Feo M, De Santo LS, Pollice A, Tedesco N, Cotrufo M. Dose-dependent fetal complications of warfarin in pregnant women with mechanical heart valves. J Am Coll Cardiol. 1999;33:1637-41.

11. Bonow RO, Carabello BA, Chatterjee K, de Leon A Jr, Faxon DP, Freed MD, et al. ACC/AHA 2006 guidelines for the management of patients with valvular heart disease: a report of the American College of Cardiology/American Heart Association Task Force on Practice Guidelines (writing Committee to Revise the 1998 guidelines for the management of patients with valvular heart disease) developed in collaboration with the Society of Cardiovascular Anesthesiologists endorsed by the Society for Cardiovascular Angiography and Interventions and the Society of Thoracic Surgeons. J Am Col Cardiol. 2006;48:e1-148.

12. Vahanian A, Baumgartner H, Bax J, Butchart E, Dion R, Filippatos G, et al. Guidelines on the management of valvular heart disease: the Task Force on the Management of Valvular Heart Disease of the European Society of Cardiology. Eur Heart J. 2007;28:230-68.

DOI: $10.18203 / 2320-1770 . i j r \operatorname{cog} 20150095$

Cite this article as: Tandon P, Puri S, Kaur B, Chaondwal S, Gupta S. Successful maternal and fetal outcome of pregnancy following heart valve replacement using a sequential anti coagulation regime. Int J Reprod Contracept Obstet Gynecol 2015;4:801-3. 